\title{
APROVECHAMIENTO DIDÁCTICO DE UN COMENTARIO LÉXICO
}

\author{
Fabián González Bachiller \\ Universidad de La Rioja
}

\begin{abstract}
RESUMEN. A partir de un breve fragmento literario, se propone un comentario léxico, por medio del cual el alumno universitario puede comprobar la relación entre lo lingüístico y el medio social y natural; se hace hincapié, para ello, en el estudio de las voces de carácter rural y regional del texto, características de La Rioja Alta.

Así mismo, se insiste en el empleo de los diccionarios como recursos imprescindibles para el dominio del vocabulario.
\end{abstract}

ABSTRACT. From a brief literary fragment, a lexico-semantic commentary is proposed, in order for the university student to prove the relation between the linguistic forms and the social and natural environment. For that purpose, the study of characteristic regional and rural words in the text is emphasized.

On the other hand, the use of dictionaries as indispensable tools for the mastering of vocabulary is highlighted.

“¿Cuán escasos los libros de texto redactados para los discípulos! ¡Cuánta pedantería! Al escribir, nos colocamos inconscientemente en la presidencia de una Academia o en el sitial de la cátedra, en vez de sentirnos sentados en los duros bancos del aula, oyendo al profesor que brega heroicamente por inculcarnos una doctrina abstrusa".

(Santiago Ramón y Cajal)

Ha transcurrido casi un siglo desde que uno de nuestros más eminentes científicos publicó esas palabras; a pesar de ello, bastantes de nuestros alumnos, de los que acuden hoy a las aulas, asentirían inmediatamente tras su lectura, ya que la situación no parece haber cambiado mucho. De ahí que, al escoger el enfoque que había de dar a mi colaboración en este número especial, me haya decidido, atendiendo a tan razonable observación, por aportar un granito de arena al montículo de los trabajos didácticos. Propongo, en consecuencia, un ejercicio dirigido al alumnado de primer y segundo ciclo universitario, y, más específicamente, al de las titulaciones de Magisterio y Filología Hispánica, en el que trato de ofrecerle algunas sugerencias metodológicas acerca de cómo comentar un texto desde la perspectiva lexicosemántica.

Hay que tener en cuenta que el desarrollo de las destrezas básicas instrumentales de la lengua es uno de los objetivos generales, tanto en la Enseñanza Primaria como en la Secundaria Obligatoria. Sin embargo, son muchos los que echan en falta en los documentos curriculares oficiales la debida atención al vocabulario, al desarrollo de 
la competencia léxica del alumnado; de ese modo, este aspecto, clave en la enseñanza de la lengua, se deja al arbitrio de los propios docentes, confiando en su actitud voluntarista.

En mi caso, anticipo ya paladinamente que no pretendo presentar teorías ni graves conceptos sobre el particular; mi objetivo es mucho más modesto: analizaré algunos de los rasgos lexicosemánticos que un texto actual, de carácter literario, ofrece, con el fin de mostrar algunas de las muchas vías por las que llegar a una suficiente interpretación del texto seleccionado; esbozaré otras y sugeriré alguna más. Entiéndase, eso sí, que todas ellas pueden conducir al objetivo propuesto y poseen claro interés en sí mismas. Por ello, debo aclarar también que tanto la elección del texto como la de esas vías de interpretación buscan una relación inmediata de lo lingüístico (en este caso, además, de lo literario) con el entorno geográfico y cultural del alumnado, ya que, como concretaré más adelante, se trata de ejemplificar la trabazón de las materias de Lengua Española con las que estudian el medio natural y el ámbito cultural que nos rodea.

Objetivos conceptuales. Nos interesa, por tanto, que los alumnos:

- Comprendan que existen distintas lenguas funcionales dentro del idioma común.

- Aprendan nuevas palabras y refuercen el conocimiento que ya tienen de otras, convirtiendo el vocabulario pasivo en activo.

- Aprendan algunos mecanismos de formación léxica, frecuentes en el español actual.

- Conozcan diversos tipos de diccionarios y repertorios léxicos: generales y dialectales o regionales; de uso; históricos y etimológicos; de sinónimos, etc.

- Profundicen en el conocimiento del medio geográfico y cultural.

\section{Objetivos procedimentales:}

- Que desarrollen destrezas en la búsqueda de información lexicográfica.

- Que desarrollen la técnica de la encuesta.

- Que manejen un vocabulario específico, técnico en algunos casos.

\section{Objetivos actitudinales:}

- Que se fomente entre ellos el respeto por las tradiciones y usos populares, así como por el medio ambiente.

- Que dialoguen dentro de la familia acerca de las experiencias vitales de los mayores y aun de los antepasados.

- Que desarrollen el interés por la historia y la cultura inmediata de su localidad o región.

- Que desarrollen el gusto por la lectura de obras literarias.

- Que se fomente el trabajo en grupo, así como el debate común en el aula.

Actividades. La tarea específica del comentario exige una lectura detenida del texto, con atención a sus rasgos descriptivos, y una serie de búsquedas lexicográficas; 
en ellas el profesor debe guiar y orientar a los alumnos, de acuerdo con el nivel correspondiente, en la utilización del material existente en el aula y en la biblioteca del centro; ello debe hacerse en grupos que manejen sendos tipos de diccionarios. Se hará una puesta en común de los resultados de las búsquedas, lo que permitirá un mejor aprovechamiento didáctico.

Previamente (o posteriormente, si se quiere utilizar el texto como arranque motivador del resto de actividades) los alumnos habrán llevado a cabo sencillas encuestas entre sus familiares y conocidos (padres, abuelos, tíos...) acerca de las labores agrícolas, pecuarias, artesanales, más características del lugar; también una recopilación de datos acerca de la flora y la fauna. La información obtenida con tales encuestas y tareas recopilatorias servirá al profesor para confeccionar un listado común del que dispondrá luego cada alumno.

A tal fin, en colaboración con los responsables de las correspondientes materias escolares, habrán esbozado una lista de voces relativa a tales temas según el español estándar (puede resultar muy interesante plasmarla en constelaciones léxicas' que permitan vislumbrar la conexión entre las diferentes actividades) y habrán comentado las cuestiones más importantes de ellas.

Como conclusión de todas estas tareas, los alumnos pueden llevar a cabo, individualmente o en grupos, un pequeño trabajo escrito, a modo de informe, acerca de la realidad social, histórica y cultural de la localidad o la zona, acompañado de un léxico glosado. Todo ello permitirá al profesor evaluar la actividad.

He aquí el breve texto elegido para su comentario:

“Aunque puse empeño en mostrarles la cara más amable de Santa Prisca, guiando sus pasos por ermitas románicas, veredas de raposas, bodegas y lagares, antiguos territorios de nutrias, escudos de alabastro, cubetas y tastavines, furtivas meriendas de truchas y blanquillo -enredados en remanga y esparavel-, casonas blasonadas, buitreras de leonados, trujales de raspones, saltos de garduña, pontones medievales, chuletadas al sarmiento, vidrieras góticas, madrigueras de tasugo, pilas bautismales y tumbas visigóticas, persecuciones de gazapos por cazadoras comadrejas, cerámicas de sigilata, verticales vuelos de milano, ruinas celtibéricas, cantos de búhos y picachas,... Práxedes encaminó sus pasos y sus obsesiones hacia el vetusto palacio medieval de almenas entejadas, foso abandonado, torreones octogonales y oscuras dependencias -dominios de lirones y plantas fotófobas-, pero que a él se le apareció como lugar encantado, por el que aún flotaba el ánima maldita de algún conde perverso, o lugar visitado por los pasos del Errabundo. Cada atardecer, antes de perdernos por la alegre senda de las bodegas, Práxedes se dirigía hacia el castillo y, en el antiguo patio de armas, rodeado de aladros, brabanes, rastras, horquillos y otros útiles agrícolas conquistados por ortigas y marrubios, tocaba con el saxo, bajo la partida ménsula de ejecutar, la partitura que Elías compusiera, al estilo de la música pavorosa de aquellas viejas producciones de la Hammer"

(Jesús Miguel Alonso Chávarri, La hipótesis del continuo, Madrid, Huerga y Fierro, 1998, pág. 152)

1. Sigo la terminología de J. F. Pastora en su libro El vocabulario como agente de aprendizaje. Madrid, La Muralla, 1990. 
Estamos ante un fragmento narrativo y descriptivo que nos ofrece la perspectiva de una persona que trata de enseñar al visitante lo mejor de su localidad, lo que el narrador designa como "la cara más amable de Santa Prisca".

Hay que advertir, en primer lugar, que este topónimo parece imaginario, puesto que, consultado el Diccionario de toponimia actual de La Rioja², no se hallan en él recogidos ni el de Prisca ni el de Santa Prisca; sin embargo, las diversas referencias que se encuentran en las obras de Alonso Chávarri permiten identificarlo con la localidad altorriojana de Leiva, sita a orillas del río Tirón ${ }^{3}$, lo que casa muy bien con la variedad lingüística que se manifiesta en este texto y que constituirá, en buena medida, el objeto de nuestro comentario.

Quien ejerce esa función de guía aparece como narrador en primera persona ("puse empeño"), subjetivo y omnisciente (no sólo dirige la narración, sino que conoce los pensamientos y sentimientos de otros personajes, como lo prueban expresiones del tipo "encaminó sus pasos y sus obsesiones"; "se le apareció como...") participante, además, en los hechos narrados ${ }^{4}$.

La organización textual del fragmento es muy sencilla:

Aunque (yo) puse empeño Práxedes encaminó Cada atardecer

En la primera parte se sintetizan los aspectos más sobresalientes de la localidad descrita en relación con: 1) el arte (ermitas románicas, vidrieras góticas, tumbas visigóticas, etc.); 2) la naturaleza (veredas de raposas, buitreras de leonados, saltos de garduña...); 3) el ocio: por una parte, en torno a la comida y la bebida (bodegas y lagares, meriendas de truchas y blanquillo, chuletadas al sarmiento...); pero también el ocio plasmado en el paseo por el campo para observar los animales citados, por la villa, para admirar el arte, en las actividades de pesca o en la preparación de las meriendas, aludida en esa "alegre senda de las bodegas".

Todo ello se ofrece en una enumeración deliberadamente caótica (dado que en su exposición no sigue una pauta, orden o sistema reconocible) de sustantivos, matizados algunos de ellos por adjetivos o por sintagmas preposicionales $y$, en algunos casos, por ambos tipos de unidades conjuntamente: ermitas románicas; veredas de raposas; antiguos territorios de nutrias. Los puntos suspensivos que la cierran dan a entender que esa enumeración no es exhaustiva y que podría aún alargarse más.

La segunda parte contrapone al plan turístico anterior las inclinaciones de uno de los personajes, Práxedes, que lo llevan por otros derroteros, concretados en lo que puede considerarse la tercera parte del fragmento: en ella cambia el tipo de enumeración (que también es más breve) y aparece ordenada temáticamente: primero aparecen los rasgos arquitectónicos del vetusto palacio; luego, útiles agrícolas (aladros, brabanes...) y elementos de la naturaleza (concretados en dos tipos de plantas: orti-

2. A. González Blanco, Diccionario de toponimia actual de La Rioja. Universidad de Murcia-IER, 1987.

3. Es la localidad natal de dicho autor.

4. Siguiendo alguna de las terminologías al uso, caso de la de Genette, hablaríamos de un narrador homodiegético. 
gas y marrubios) forman parte del escenario en que el personaje ejecuta con su saxo la música de la partitura.

$\mathrm{Si}$ intentamos estudiar con detenimiento este fragmento desde el punto de vista léxico, se abren ante nosotros, inmediatamente, diversas posibilidades. Así, cabe discernir en detalle un léxico decididamente culto e, incluso, técnico y especializado (casos de: sigilata, octogonales, fotófobas, ménsula, pavorosa...) junto a otro de carácter tradicional (aunque en algunos casos pueda resultar también demasiado especializado y, por ello, difícil para el lector medio): bodegas, lagares, cubetas, meriendas, buitreras, chuletadas, etc.

Puede ser también de gran interés -sobre todo en los niveles de enseñanza primaria, pero también en los de secundaria- agrupar y clasificar las voces en campos temáticos; ello permitirá comprobar cómo se entrecruzan voces relativas al arte (ermitas románicas, escudos de alabastro, casas blasonadas, pontones medievales, vidrieras góticas, tumbas visigóticas, sigilata...) con otras relativas al ocio (bodegas y lagares, cubetas, tastavines, furtivas meriendas, chuletadas al sarmiento, etc.); varias más que aluden a la naturaleza, fauna y flora (veredas de raposa, territorios de nutrias, truchas y blanquillo, ortigas, marrubios, etc.) junto a unas pocas alusivas a las actividades agrícolas (aladros, bravanes, rastras...) o al ámbito de lo musical: saxo, partitura, componer.

O acaso el interés inmediato estribe en comprobar fenómenos de formación léxica: la presencia de unidades pluriverbales o fraseológicas ${ }^{6}$, como locuciones y colocaciones del tipo puse empeño (colocación no consolidada aún en la lengua y no recogida por el DraE ni por el DeA7); encaminó sus pasos (colocación, no recogida por el DraE ni por el DeA); patio de armas (colocación; el DraE recoge plaza de armas, pero no patio de armas; en cambio, sí la incluye el DEA); chuletadas al sarmiento (colocación, ausente del DraE y del DeA); pilas bautismales (locución recogida por el Drae y el Dea).

5. Empleo este término en sentido lato, considerando que no es momento adecuado para introducir problemas terminológicos en torno a los llamados campos léxicos, campos semánticos o, incluso, campos lexicosemánticos; cabe interpretar que estos campos temáticos pueden acercarse a lo que Coseriu (Principios de semántica estructural, pág. 43) llama campo conceptual.

6. El término unidad fraseológica es el que se está imponiendo en la lingüística española, siguiendo propuestas como las de G. Corpas (Manual de fraseología española. Madrid, Gredos, 1996), L. Ruiz (Aspectos de fraseología teórica española. Valencia, Universidad, 1997), etc. Empleo aquí el término colocación para designar aquellas unidades fraseológicas no fijadas aún en el sistema, lo que las distingue de las locuciones, que sí cuentan con un reconocimiento externo de su fijeza. En este caso, podemos hacer ver a los alumnos, como criterio práctico, que algunas de esas expresiones (locuciones) se recogen en los diccionarios, por su frecuencia y por la relativa antigüedad de uso; otras (colocaciones), no cumplen todavía estos requisitos.

En relación con la búsqueda de tales expresiones en los diccionarios, ha de insistirse entre el alumnado que su inclusión se hace en alguna de las palabras "fuertes" de la expresión (sustantivo, si lo hay, como empeño en la expresión poner empeño) y no en la primera de las palabras que la componen.

7. El Diccionario de la Lengua Española de la Real Academia Española (22a edición del año 2001, conocido habitualmente como DRAE) debe ser el de consulta habitual para el alumno universitario; además, en ciertos casos, conviene consultar alguno que recoja el vocabulario más actual, como es el caso del Diccionario del español actual (Madrid, Aguilar, 1999) que cito como DeA. 
O también pueden estudiarse fenómenos de acortamientos léxicos como saxo (creado desde saxófono o, quizás, desde el más popular saxofón); o el uso de voces compuestas como tastavines, remanga, celtibéricas, octogonales, fotófobas; de la abundante derivación (-ón, -ona: casonas, pontones, raspones; -era: buitreras, vidrieras, madrigueras), y hasta se puede hacer ver, en niveles superiores, la explicación de entejadas como un fenómeno de parasíntesis; y así algunos otros ejemplos.

Desde el punto de vista de las relaciones lexicosemánticas puede insistirse en la presencia de voces polisémicas como cara (en la acepción 9ạ del DrAE, 'Aspecto o apariencia de una cosa o asunto, aunque cabe aceptar que se haga una aplicación metafórica de la $3^{\text {a }}$ que la hace sinónima de semblante); gazapo ('Conejo nuevo'; para el DRAE es un caso de homonimia, aunque no queda claro que se trate de dos palabras de origen etimológico diferente); tocar (en el texto vale 'interpretar una pieza musical', acepción 4⿳亠丷厂 del DRAE); componer (aquí 'Producir obras musicales', acepción

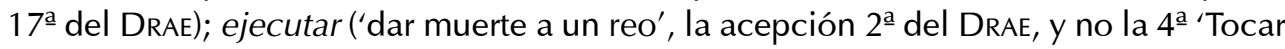
una pieza musical', ya que la ménsula podía servir para colgar a los condenados); dependencias (acepción 7 $7^{a}$ 'Cada habitación o espacio dedicados a los servicios de una casa) y otras más.

No hay un empleo claro de la sinonimia, aunque necesariamente habrá que comentar que en el texto el autor, hay que suponer que intencionadamente, la establece entre palacio y castillo, ya que aplica una y otra voz a la misma realidad; en niveles superiores puede comentarse la hiperonimia establecida entre útiles agrícolas y sus concreciones léxicas: aladros, rastras, etc. También puede subrayarse, para los alumnos de Filología la fundamentación eufemística, desde el punto de vista de la historia de la lengua, de las voces comadreja y raposa ${ }^{8}$.

En suma, la riqueza léxica del fragmento, su variedad, permite abordarlo desde muy diversos ángulos. En este caso, vamos a centrar nuestras indagaciones en lo que atañe al léxico de lo rural, precisamente porque nos interesa mostrar cómo se ha aprovechado en este texto para teñirlo de sabor regional y cómo éste, al igual que otros muchos ejemplos parecidos, puede servir de acicate para que los alumnos de distintos niveles educativos lleven a cabo, al hilo de sus tareas escolares, el acopio, estudio y comentario de voces tradicionales de su propio ambiente; actividad que suele resultar didácticamente muy fructífera.

Utilizaremos así el medio como recurso didáctico, para favorecer el aprendizaje del vocabulario de una zona, con sus peculiaridades geográficas, históricas...

Este planteamiento ayuda a ampliar el vocabulario y mejorar su dominio, al tiempo que afianza el conocimiento del propio medio ambiente, de las actividades de la población (artesanas, agrícolas, ganaderas), así como de la historia, reciente o pretérita, del entorno. El comentario de texto puede en tal caso establecerse como activi-

8. El alumnado al que se dirige este trabajo (no digamos ya el de Filología Hispánica) debe conocer y manejar el Diccionario crítico etimológico castellano e hispánico de J. Corominas y J. A. Pascual, publicado en 6 volúmenes por la editorial Gredos; lo cito en adelante con las siglas DCECH; en él se comenta pormenorizadamente el origen de las denominaciones de tales animales, motivadas por el temor hacia ellos. 
dad paralela o bien preparatoria del estudio del medio, aprovechando la interdisciplinariedad de estos temas.

Todo ello se fundamenta en la existencia de una mayor motivación en el alumno, dado que de este modo trabaja en algo que ve como propio o, al menos, como muy cercano a sus intereses personales. En el caso del área de Lengua Española se pretende concretamente, con tales ejercicios, afianzar el dominio del vocabulario con unas tareas léxicas, lexicográficas y dialectales que, además, ayuden a comprender que la lengua general no es algo monolítico y rígido, de una sola pieza, sino que contiene elementos (concretamente elementos léxicos) variados; algunos de ellos pueden ser caracterizadores de una región, y otros pueden alcanzar el carácter de verdaderos localismos.

Imaginemos que, dentro de esa actividad, deseamos que hagan una recopilación de voces alusivas a los animales característicos de la zona, sus movimientos y comportamientos. En el propio texto hallamos las siguientes expresiones, que componen un elenco bastante representativo de la fauna de una región:

Veredas de raposas; nutrias; truchas y blanquillo; buitreras de leonados; saltos de garduña; madrigueras de tasugo; persecuciones de gazapos por cazadoras comadrejas; vuelos de milano; cantos de búhos y picachas; dominios de lirones.

Además, remanga y esparavel designan medios para pescar.

Si nos centramos en el estudio de la actividad agrícola, podemos entresacar del fragmento:

bodegas y lagares; cubetas y tastavines; trujales de raspones; aladros; brabanes; rastras; horquillos; útiles agrícolas.

Es de suponer que una parte de las voces hasta aquí relacionadas no presenta ninguna dificultad de comprensión para un hablante medio y, por tanto, para el alumnado universitario e incluso el de enseñanza secundaria. Es el caso de: gazapo, nutrias, truchas, madrigueras, bodegas, lagares, raposas, rastras, trujales, útiles agrícolas.

Solamente cabe hacer notar que en el caso de rastras el contexto no contiene más especificaciones $y$, por ello, no es posible concluir si aluden al apero conocido también como grada ('Instrumento de madera o de hierro, de forma casi cuadrada, a manera de unas parrillas grandes, con el cual se desmenuza y allana la tierra después de arada, para sembrarla') a que el DrAe se refiere en la acepción $4^{a}$ de esa voz, o a la que incluye como $5^{\text {a.: }}$ 'Tabla que, arrastrada por una caballería, sirve para recoger la parva de la era'.

En cuanto a raposa, cabe indagar, entre los propios alumnos, si es más usual en la comarca esta denominación o la de zorra, dando ya por sentado que vulpeja apenas resulta conocida fuera de los textos literarios.

Tampoco la voz gazapo 'cría del conejo' debe ofrecer dificultades; en todo caso, no estará de más comentar la acepción escolar (el DraE la tilda de "coloquial") 'Yerro que por inadvertencia deja escapar quien escribe o habla', cuyo origen no está suficientemente aclarado; igualmente, hay que recordar el verbo derivado, agazaparse: coloquialmente 'Agacharse, encogiendo el cuerpo contra la tierra, como lo hace el gazapo cuando quiere ocultarse de quienes le persiguen'. 
Otras varias voces corresponden al español general, aunque no formen parte del vocabulario activo del hablante medio e incluso puedan plantear dificultades de comprensión. Precisamente por ello, resultará conveniente programar actividades léxicas y lexicográficas encaminadas específicamente a su conocimiento cabal, de acuerdo con el nivel concreto de enseñanza en que nos encontremos. Ello permitirá insistir nuevamente en el manejo de los diccionarios como medio para afianzar el dominio del vocabulario.

Puede comenzarse esta tarea, a modo de ejemplificación, con la palabra vereda, que posee hoy carácter de voz restringida, ajena al vocabulario usual; el diccionario académico la define como 'Camino angosto, formado comúnmente por el tránsito de peatones y ganados' y, en una segunda acepción, 'Vía pastoril para los ganados trashumantes, que, según la legislación de la Mesta, es, como mínimo, de 25 varas de ancho'. Parece claro que el texto hace uso de la primera acepción, con el matiz añadido de que se trata, en este caso, de un camino creado por las raposas en sus idas y venidas.

Gili Gaya ${ }^{9}$ la hace voz casi sinónima de senda y de sendero; interesa hacer hincapié en que tiene relación semántica con atajo y trocha, y que la segunda de las acepciones consignadas arriba la relaciona con cañada y cordel, voces estas últimas que vuelven hoy a resonar con la recuperación de las viejas vías pecuarias peninsulares ligadas a la trashumancia.

Además, desde la perspectiva dialectológica, que debe formar parte del bagaje de conocimientos del alumno de Filología Hispánica, nos interesa en este caso otra acepción, que el DRAE recoge como $5^{\underline{a}}$ con el marbete de coloquial y restringida a Álava: 'Prestación personal'. El interés proviene del hecho de que, como ya indicaba Goicoechea $^{10}$, es de uso bastante común en La Rioja, especialmente en Rioja Alta, en acepción semejante: 'Prestación personal para la ejecución de obras de carácter público municipal'. Podemos comprobarlo acudiendo a otro texto del mismo Alonso Chávarri: "padre nos avisa desde el pórtico de San Marcial, donde hace mortero con Ananías, pues hay vereda para arreglar las escaleras del coro" (Tasugo, 95); como dato para la historia de la lengua y para la historia de la cultura española, puede subrayarse que el primer texto donde aparece este empleo es en el Fuero de Logroño (¿de 1095?), en el que se exime a sus pobladores de colaborar en la construcción y reparación de caminos y puentes al prescribir: "neque ulla vereda faciant".

Para completar el abanico de posibilidades abierto por esta palabra, cabe recordar las locuciones meter a alguien en vereda o hacerle entrar en vereda, que el diccionario académico explica como 'Obligarle al cumplimiento de sus obligaciones'; son expresiones no recogidas por Covarrubias ni por Autoridades" ${ }^{11}$. Es interesante insistir

9. S. Gili Gaya, Diccionario de sinónimos. Barcelona, Vox, 1988.

10. C. Goicoechea, Vocabulario riojano. Madrid, Anejo VI del BRAE, 1961.

11. El Tesoro de la lengua castellana o española de S. Covarrubias, se publicó en 1611 (hay reedición en Barcelona, Alta Fulla, 1989); Autoridades es como se conoce el primer diccionario confeccionado por la Real Academia Española, el Diccionario de la lengua castellana, publicado entre los años 1726 y 1739 (hay reedición en Madrid, Gredos, 1984); ambas son obras que deben ser consultadas inexcusablemente por todos los interesados en la lengua y la literatura de la época clásica española, así como en la historia de nuestra lengua. 
en que tal sentido parece estar en relación directa con el hecho de ver el camino, la vereda, como 'lo recto y adecuado', de modo que quien está fuera está descarriado y, por ello, hay que hacerle volver al camino marcado o "buen camino".

Veamos las consideraciones didácticas que sugieren otras voces del texto.

Buitrera nos puede servir para recordar las variadas formaciones a que da lugar el sufijo -era: por un lado, como formador de adjetivos del tipo soltera, enfermera, etc.; por otro, dando lugar a sustantivos, lo hallamos tanto con carácter abundancial (chopera) como con el valor de lugar de cría o de depósito (leonera, escombrera); ello puede propiciar ejercicios de interpretación semántica a propósito de otras voces comunes y usuales como bañera, bolera, borrachera, higuera, lechera, etc., lo cual resulta una actividad de buen rendimiento didáctico.

Leonados remite al buitre leonado o, técnicamente, Gyps fulvus, ave presente en sistemas montañosos del Centro y Sur de la Península, el Sistema Ibérico y los Pirineos; suele habitar en cortados calizos y no está amenazada de extinción aunque es poco abundante. Según el DraE, leonado es adjetivo: 'De color rubio oscuro, semejante al del pelo del león', lo que hace fácilmente explicable la denominación de estas aves aludidas.

Milano puede aludir tanto al milvus migrans, o milano negro, como al milvus milvus, milano real; desde el terreno léxico cabe hacer reflexionar al alumnado acerca de la denominación genérica de rapaces (aplicable, igualmente, a otro de los animales citados en el texto, el búho, ave definida como 'rapaz nocturna') así como la fundamentación semántica del verbo amilanar ('intimidar, amedrentar') constatado ya en castellano en los escritos de Santa Teresa, y amilanarse ('abatirse o desalentarse'); hallada esa explicación, puede afianzarse el fenómeno con las voces azorarse y azorado, que presentan un fenómeno semántico muy semejante.

La garduña 'mamífero carnicero nocturno' es animal poco conocido, por lo que el alumno deberá indagar sus rasgos en diccionarios y enciclopedias; además, posee esta voz otra acepción que al estudioso de la Filología le interesa conocer, ya que aparece en textos literarios ${ }^{12}$ : 'ratero que hurta con maña y disimulo'; es una acepción explicable precisamente por la propia conducta del animal, nocturno y huidizo, al que se considera muy dañino. Es bien conocida en español la tendencia a usar apelativos de animales para caracterizar las conductas negativas (más frecuentemente que las positivas) de las personas y esto puede propiciar el comentario de otros ejemplos semejantes en el aula.

En cuanto al lirón, probablemente forme parte del vocabulario activo gracias a la expresión dormir como un lirón, que el diccionario académico incluye como frase coloquial con el significado de 'dormir mucho o de continuo'; no estará de más recordar que la causa estriba en que se trata de un animal mamífero roedor que pasa todo el invierno oculto y adormecido, manteniendo una incesante actividad el resto del año. Siguiendo la tendencia ya comentada antes, se dice de alguien que es un lirón cuando duerme mucho y nada lo saca de su sueño ${ }^{13}$.

12. Así en el propio título de La garduña de Sevilla y anzuelo de las bolsas, de Alonso Castillo Solórzano, publicada en 1647; es novela de las Ilamadas picarescas, de protagonista femenino.

13 Alterna en la misma expresión y valor con la voz marmota, que designa un roedor de características y costumbres muy semejantes. Se puede consultar el Diccionario ideológico de la lengua espa- 
$\mathrm{Ni}$ remanga ni esparavel son voces que formen parte del vocabulario usual de los hablantes, pero sí pueden ser conocidas por los amantes a la pesca, puesto que ambas aluden a artes de pesca fluvial empleadas por una sola persona para capturar barbos, cangrejos, etc.

Además de todas estas voces, pertenecientes a la lengua general española, aparecen en el fragmento otras que tienen un uso restringido geográficamente; en algunos casos, como vamos a ver, esa limitación se reduce incluso al ámbito de lo local o comarcal. Esto habrá de tenerse muy en cuenta para insistir en la relación con el medio.

En lo que corresponde a los animales, hay que considerar entre las de tal carácter el blanquillo, las picachas y el tasugo.

En el caso de blanquillo puede colegirse, por su presencia inmediata a la voz truchas, que se trate de un pez; si el alumno acude al DraE podría corroborar esta intuición, puesto que s. v. blanquillo, en su acepción 4. consigna: 'Pez chileno, de unos tres decímetros de longitud, de color rojizo más o menos pardo por el lomo y plateado por el vientre'. A la vista de tales datos, lo que habría que preguntarse inmediatamente es por qué un pez chileno aparece entre lo más característico de la localidad española de Santa Prisca.

La respuesta es que no debemos dar por válida esta información para el texto que nos ocupa, ya que nos hallamos ante una voz regional, riojana; si acudimos al ya citado Vocabulario riojano, comprobaremos que la segunda acepción consignada en la voz blanquillo es 'Pez del tipo de la boba, aunque mayor que ella, de color parduzco y sabor algo amargo y desagradable'; no cita Goicoechea localidades de uso, por lo que da a entender que se trata de una palabra extendida por toda la región; en cuanto a la boba, la define como 'Pez de color negruzco con vientre blanco' y limita la constatación de su uso a la localidad altorriojana de Nájera.

La voz picachas parece una variante fonética de picazas, una de las muchas formas existentes en nuestra lengua para designar a las urracas. El DRAE remite directamente de picaza a urraca, igual que hace en la entrada picaraza. Esta forma picacha no figura consignada en el ya citado Vocabulario riojano, por lo que parece tener todo el carácter de localismo o limitarse sólo a la zona inmediata a Leiva, pues no se halla consignada así tampoco en otros repertorios léxicos relativos al habla de La Rioja.

La búsqueda de tasugo en el diccionario académico resultará vana, ya que no recoge esta variante; sí, en cambio, la de tajugo, con la que se halla fonética y léxicamente emparentada y que circunscribe a Aragón; para su significado remite a la voz tejón, que es la general en español. Sin embargo, como se advierte en el DCECH, s. v. tejón, tessugo está ya en la obra de don Juan Manuel; taxugo en el Glosario de Palacio y texugo en el Glosario de Toledo; y, en el habla contemporánea, se afirma en la misma obra que la forma tasugo es la más extendida por las provincias de Burgos, Ávila y Soria. Claro que ahí no cita a La Rioja; Goicoechea incluía la forma apoco-

ñola, Barcelona, Bibliograf, 1995, dirigido por Manuel Alvar Ezquerra, en la sección dedicada al 'descanso', y se comprobará que sólo aparecen recogidas allí estas dos referencias animales. El Diccionario de argot de J. Sanmartín recoge la expresión como locución y la documenta ya en Tirso de Molina. 
pada tajú, usual en la localidad riojabajeña de Cervera del Río Alhama, pero no esta de tasugo; sin embargo, da fe de la vitalidad de esa variante en La Rioja Alta el hecho de que en la toponimia de la zona aparezcan con bastante frecuencia los topónimos La Tasuguera, Las Tasugueras, además de Las Tajugueras.

Continuando con lo que atañe a voces no correspondientes a la lengua general, sino que tienen un carácter regional, podemos comentar las voces relativas a lo agrícola; aparecen en el texto: raspones, cubetas, tastavines, aladros, brabanes, horquillos.

Observaremos primero que raspón no tiene en el diccionario académico acepción que encaje en el texto, ya que sólo alude a su equivalencia con rasponazo 'erosión superficial' y al significado que posee en Colombia de 'Sombrero de paja'; sin embargo, el DEA incluye la voz como regionalismo (sin especificación concreta) con el significado de 'Escobajo [del racimo de uvas]'.

Podemos aquilatar mejor su empleo si observamos primero los datos de Goicoechea, que en su Vocabulario incluye raspón como 'Escobajo, raspa de un racimo', usado en Logroño y otros lugares; aún más datos aporta la información proporcionada por Conde ${ }^{14}$, según la cual, para el escobajo o 'raspa que queda del racimo después de quitarle las uvas' se emplean en La Rioja generalmente las voces raspa y raspón; esta última variante, que es la que nos interesa, se constata en las localidades de San Román, Torrecilla, Albelda, Tobía y la de Casalarreina, que se encuentra muy cercana a la zona reflejada en el texto.

La voz cubeta presenta en el DrAE dos acepciones más o menos cercanas a la que hallamos en el fragmento elegido: la primera de las que consigna el diccionario es 'Herrada con asa hecha de tablas endebles'; aún resulta más interesante la $6^{\text {ă: }}$ 'Cuba manual que usaban los aguadores'; en ambos casos se alude a una vasija hecha de madera, aunque no coincide íntegramente con el tipo de la aludida en el texto. Indudablemente cubeta es una formación de diminutivo a partir de cuba, mediante el sufijo de diminutivo -eta; de esa formación pueden verse en el aula ejemplos del tipo vagón/vagoneta; trompa/trompeta, etc. Se trata, en fin, de una 'cuba pequeña', de menor capacidad, por tanto, que las grandes cubas de las bodegas; he aquí otra referencia textual del mismo autor: "Rosito saca de la cubeta joven unas jarras de clarete" (Tasugo, 40).

En cuanto a tastavines, se trata de una voz que presenta varias peculiaridades; por una parte, es voz de uso limitado, tanto en lo geográfico (las referencias conocidas, tal como se verá a continuación, corresponden a las zonas de Aragón, Navarra y La Rioja) como en su frecuencia; por ello el DrAE no la consigna ni en esta variante ni en la de tastarín, recogida en su día por el aragonés Borao ${ }^{15}$ con la acepción concreta de 'Cata del vino' en la expresión "dar tastarín a la cuba". Dicha frase es parecida a la que recoge Iribarren ${ }^{16}$ en Buñuel y la Ribera tudelana: "hacer un testavín": 'Extraer una pequeña porción del vino de una cuba por el orificio llamado ceril, para comprobar el color, sabor, etc. de aquél'; y también es semejante la que Goicoechea incluye en

14. M. C. Conde, Contribución al estudio del léxico agrícola riojano. Logroño, IER, 1994.

15. J. Borao, Diccionario de voces aragonesas. Zaragoza, Imprenta del Hospicio Provincial, $1908^{2}$. 16. J. M. Iribarren, Vocabulario navarro. Pamplona, $1984^{2}$. 
su Vocabulario, localizada en Cervera del Río Alhama: dar tastavín, que, dice, "equivale a estrenar los toneles de vino nuevo", dado que tastavín es la 'Espita de madera' que se coloca en toneles o cubetas para facilitar la extracción de su contenido.

Su origen es discutido: ya Iribarren, tras su definición, apuntaba a un posible origen francés (occitano taster, francés tâter), aunque me parece más plausible la explicación como palabra compuesta del antiguo occitano y riojano tastar 'golpear' y también 'probar, catar' (ya en Berceo "que de mejor bocado non podriedes tastar") más el sustantivo vino. (La alternancia de la vocal átona, sobre todo seguida de -s- no es nada extraña en nuestra zona, como se ve en astilla / estilla).

El mismo autor de este fragmento usa la voz, escrita con -b- en otras obras: "Antes de quitar el tastabín a la cubeta de dieciséis cuartillas y emborracharnos" (De buena fuente, 154).

Los aladros que se citan en el fragmento son los arados tradicionales de madera. Ya el DCECH, al comentar el verbo arar, indica que desde el latín ARATRU surgió (por disimilación de $r . . . r>$ I...r) aladro, variante que se conserva aún hoy, dice, en Aragón y la montaña de Burgos; no cita ahí a La Rioja, pero ya consignaba esta voz Goicoechea sin especificar localidades, al entender que era de uso común, así como la de aladrero 'Artesano que construye los arados', profesión ya en desuso (este ejemplo puede propiciar el comentario de otros apodos típicos de los pueblos, alusivos a profesiones y actividades que han desaparecido: albardero, soguero, estañador, etc.); también dan fe de su empleo en el ámbito riojano otros dialectólogos como Merino Urrutia y A. Llorente ${ }^{17}$.

No registra el DRAE la palabra brabán; pero García Turza ${ }^{18}$ comenta su empleo en la localidad riojana de Matute: 'Moderno arado giratorio, arrastrado por tractor o caballerías'; se constatan, en diversos trabajos dialectales, el objeto y la denominación en Álava, Navarra y la comarca burgalesa de la Bureba. Es, por tanto, un tipo de arado más moderno y de mejores prestaciones, que aún llevan los actuales tractores. García Turza alude al origen francés de esta voz (desde bravant), pues probablemente también el apero vino desde allá.

El diccionario académico no incluye la voz horquillo en tal forma, pero sí en la femenina, horquilla, como equivalente de horca 'Herramienta en forma de horca de labrador para diversos usos'. García Turza especifica que en Matute se trata de 'Instrumento para cargar estiércol, está formado por un mango largo de madera y cinco o seis dientes curvos metálicos' y alude a parecida definición por parte de Iribarren. También incluye como segunda acepción la de 'Instrumento para dar vuelta y ablentar, compuesto de un palo largo en cuyo extremo hay un travesaño con cuatro, cinco o seis gajos de madera', lo que, en ambas acepciones, también se conoce como albiendo, bieldo.

17. J.J.B. Merino Urrutia, "Vocabulario de la cuenca del río Oja", Berceo, LXXXV, 1973, 229-282; A. Llorente, "Algunas características lingüísticas de La Rioja en el marco de las hablas del valle del Ebro y de las comarcas vecinas de Castilla y Vasconia", Revista de Filología Española, XLVIII, 1965, 321-350.

18. C. García Turza, Matute y su léxico. I. Labores agrícolas. Logroño, IER, 1975. 
Conclusión. En suma, vemos así cómo este texto, de gran riqueza léxica, presenta bastantes voces que, aun perteneciendo a la lengua general española, no forman parte del vocabulario usual de los hablantes, ya que corresponden a un léxico rural especializado. Otras se apartan de la lengua general porque son de uso regional, y ello obliga, para su cabal comprensión, a indagar en repertorios léxicos de tipo dialectal. Para el alumno deben servir de ejemplo de la variedad dentro de la unidad de la lengua española; si tenemos en cuenta que algunas de las actividades y realidades a que aluden están desapareciendo, añadimos un nuevo interés a su conocimiento, por su carácter de historia cultural reciente.

Todas estas tareas encuentran, en fin, su verdadera justificación en lo interdisciplinar: se trata de aprovechar el texto como sugeridor de actividades que relacionen lo lingüístico con el medio social y natural. En unos casos, como ya se ha dicho, puede servir de motivo desencadenante de tales actividades, procediendo, por ejemplo, después a una recogida de vocabulario local, a su estudio y clasificación temática, etc. En otros casos puede ejemplificar temas que se están estudiando en otras materias escolares y servir así de colofón.

Puede resultar conveniente, tal como se ha aludido ya, desarrollar, en relación con este léxico, aspectos como el conocimiento que de él se tiene en el entorno familiar del alumno, de modo que sea éste quien pueda encuestar a sus familiares acerca de esas voces y de las actividades que implican: si se llevaban a cabo hasta fechas recientes, cuándo se han dejado de realizar, etc.

Ateniéndonos al punto de vista estrictamente lingüístico, las actividades realizadas con textos como el propuesto permiten trabajar detenidamente en la comprensión de mecanismos de la formación léxica (formación de palabras, creación de unidades fraseológicas) y fenómenos lexicosemánticos (polisemia, sinonimia, eufemismos); a ello se suman las prácticas lexicográficas, que permitirán insistir en el uso del diccionario como auxiliar imprescindible en toda tarea lingüística.

\section{Bibliografía}

ALONSO CHÁVARRI, J. M., Tasugo. Madrid, Ediciones Libertarias, 1995. , La hipótesis del continuo. Madrid, Huerga y Fierro, 1998.

ALVAR EZQUERRA, M. (dir.), Diccionario ideológico de la lengua española. Barcelona, Bibliograf, 1995.

BORAO, J., Diccionario de voces aragonesas. Zaragoza, Imprenta del Hospicio Provincial, $1908^{2}$.

CALERO HERAS, J., Entre palabras. Barcelona, Octaedro, $1994^{2}$.

CONDE SOLDEVILLA, M. C., Contribución al estudio del léxico agrícola riojano. Logroño, IER, 1994.

COROMINAS, J. y PASCUAL, J. A., Diccionario crítico etimológico castellano e hispánico. 6 vols. Madrid, Gredos, 1980-91.

CORPAS PASTOR, G., Manual de fraseología española. Madrid, Gredos, 1996. 
GARCÍA TURZA, C., Matute y su léxico.l. Labores agrícolas. Logroño, IER, 1975.

GILI GAYA, S., Diccionario de sinónimos. Barcelona, Vox, 1988.

GOICOECHEA, C., Vocabulario riojano. Madrid, Anejo VI del BRAE, 1961.

GONZÁlEZ BLANCO, A., Diccionario de toponimia actual de La Rioja. Universidad de Murcia-IER, 1987.

IRIBARREN, J. M., Vocabulario navarro. Pamplona, $1984^{2}$.

LLORENTE MALDONADO DE GUEVARA, A., "Algunas características lingüísticas de La Rioja en el marco de las hablas del valle del Ebro y de las comarcas vecinas de Castilla y Vasconia", Revista de Filología Española, XLVIII, 1965, 321-350.

MALDONADO, C., El uso del diccionario en el aula. Madrid, Arco/Libros, 1998.

MERINO URRUTIA, J. J. B., "Vocabulario de la cuenca del río Oja", Berceo, LXXXV, 1973, 229-282.

PASTORA HERRERO, J. F., El vocabulario como agente de aprendizaje. Madrid, La Muralla, 1990.

REAL ACADEMIA ESPAÑOLA, Diccionario de la lengua castellana. Madrid, 17261739. Hay edición facsímil en 3 vols. Madrid, Gredos, 1984. Diccionario de la lengua española. Madrid, Espasa, $2001^{22}$.

SÁNCHEZ GALINDO, F., "El espacio territorial de la huerta de Murcia como soporte paisajístico de un vocabulario peculiar", en Amelia Cano (coord.), Lengua y literatura: su didáctica. Homenaje a la profesora Carmen Bautista Martín, Universidad de Murcia, 1993, 315-329.

SANMARTíN SÁEZ, J., Diccionario de argot. Madrid, Espasa, 1999.

SECO, M.; Andrés, O.; Ramos, G., Diccionario del español actual. 2 vols. Madrid, Aguilar Lexicografía, 1999. 